\title{
Thermal and Cost Analysis of a Multi-Pass Solar Air Heater with Reversed Absorber and Reflector
}

\author{
Vijay R. Khawale, Assistant Professor, DBACER Nagpur, India, vijay.khawale46@gmail.com \\ Bhojraj N. Kale, Assistant Professor, DBACER Nagpur, India, bhojrajkale@gmail.com
}

Abstract: Solar air heater is a major component of solar dryer. A model of multi pass solar air heater (MPSAH) with reversed absorber and reflector was developed. Exhaustive Study over the performance of MPSAH with and without reversed absorber and cost analysis was done. The performance curves show the effect of solar intensity on MPSAH with and without reversed absorber at constant mass flow. It was observed that the thermal efficiency of MPSAH is depending on solar intensity and losses when mass flow rate remain constant. At constant mass flow rate $26.90 \mathrm{gm} / \mathrm{sec}$, the collector efficiency increased by $9 \%$ at average solar intensity $457 \mathrm{w} / \mathrm{m}^{2}$. Theoretical and experimental analysis showed close agreement. In addition the cost-effectiveness model has been used to examine the performance MPSAH with and without reverse absorbers. The air heaters annual cost (AC) estimation and annual power acquirement (AG) was analyze. The result is evidence for that multi-pass solar air heater with reverse absorbers and reflector is more cost-effective than multi-pass solar collectors without reverse absorber.

Keywords - Multi-pass, Solar air heater, Reversed absorber, Thermal performance, Cost analysis

\section{INTRODUCTION}

The solar air heater is the major components of solar crop dryer. A hot air obtained from these SAH used for various applications [1]. A different kind of SAH has been study in the literature. The factors like Thermal performance, cost and life of dryer, Installation easiness, durability and maintenance must be consider while design the SAH. Thermal efficiency used to compare the performance of SAH. Thermal efficiency of SAH is the main criteria to study the thermal performance [2-5]. However, from the low thermal efficiency it can be proved that the SAH having a lot of shortcoming. To accomplished substantial improvement in SAH thermal efficiency have need of an extended surface to increase heat transfer rate, such as finned absorber [6-10], absorber with slats [11], corrugated surfaces [12-16], porous media [17-19], box-type absorber [20], and compound honeycomb collector [21]. Naphon [22] proposed double pass solar air collector with fins and found a thermal efficiency of about 30 to $60 \%$. Metwally et al. [23] has been analyzing the thermal performance of advanced SAH with corrugated duct. The performance of same collector was compared with other types of SAH. In first type of collector, the air flows through a passage form between the absorber plate and glass cover. In second type of collector, the air flows through the passage form between the absorber plate and insulated bottom. In third type, the air flows through the passage form between the glass cover and absorber plate and latter passage form between absorber plate and bottom insulated plate. In fourth type, the absorber was made up with 50 rows of $\mathrm{V}$-folded strips and air flows above and below the absorber plate. In fifth type, a porous absorber consists of three overlapped layers of metallic mesh screens fixed diagonally along the length of the collector. Jain (24) studied a new type of SAH including reversed absorber with reflector and found satisfactory performance. Choudhury et al. [25, 26] analyze the double and triple pass SAH and noted the performance and cost analysis. Choudhury et al. [26] reported that the performance of double pass SAH was found cost effective as compared to single cover SAH. Choudhury et al. [27] also compare the triple pass SAH with the double pass and single pass SAH. Biondi et al. [27], Studied seven different kind of SAH. Now a day's Flat plate collectors are widely used. SAH used for low and medium temperature applications are accounts for more than fifty percent of the total cost of SAH. So that to make a SAH cost effective the thermal efficiency of the collector must be satisfactory. Economic optimization of SAH is available I the literatures. The present work is limited to study of MPSAH with and without reverse absorber by evaluating a ratio of annual cost and the annual energy gain of the collector.

\section{EXPERIMENTAL SeT UP}

A schematic diagram of a MPSAH with a reverse absorbing plate and reflector is shown in Figure 1. The major components of MPSAH are listed. i. Two absorbing plate made up of aluminum material painted by black colored.ii. $4 \mathrm{~mm}$ thick two plain and transparent glass covers. iii. Reflector of aluminum foil. 
Reflector contains five flat surfaces in semi circular shape attached below the absorber plate- II. Reflector used to transferring the solar radiation on absorber plate II Overall size of solar air heater is $1 \mathrm{~m} \times 2 \mathrm{~m}$. Absorber plate $\mathrm{I}$ and Glass cover I, II are overlaps each other with distance of 2.5 $\mathrm{cm}$. Solar air heater has been inclined at 31 degree to ground surface towards south to utilized maximum solar energy. Initially ambient temperature air passes through glass cover I and glass cover II and later it passes through a gap formed between glass cover II and absorber plate I and gets heated due to solar radiation Finally air gets heated and attained a high temperature due to absorbing the heat from both absorbers plates as it passes through a passage formed between absorber plate I and absorber plate II [28].

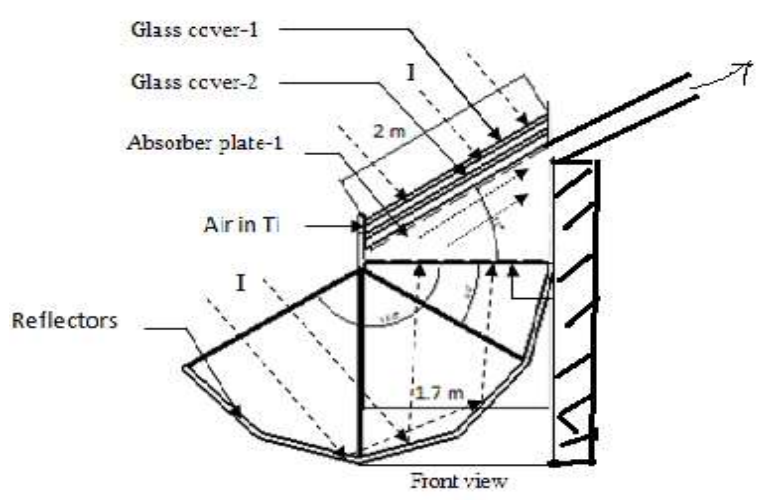

FIGURE 1 Schematic diagram of MPSAH with reversed absorber and reflector

\section{THERMAL ANALYSIS}

A solar radiation falls on glass cover and reflector through which they transfer the heat energy to both absorber plates. The air gets heated by absorbing the heat energy from solar radiation and absorber plates. Theoretically the energy balance equations are written on various components of MPSAH with the assumptions mentioned below.

i) Thermal conductivity assumed negligible for insulation material, ii) No temperature difference along the thickness of glass cover Iii) No air leakages in system. iv) One dimensional air flow and quazi steady state condition v) all convection heat transfer coefficients in all passages are equal and constant, vi) Thermal conductivity of absorber is constant, vii) The useful heat gain to the air is uniform along the length of the collector $[29,30]$.

Energy balance equation for

(a) Glass cover-1

$I \alpha_{g} A_{g_{1}}+H r g_{2} g_{1}\left(T g_{2}-T g_{1}\right) A g_{1}=H c g_{1} f_{1}\left(T g_{1}-T f_{1}\right) A g_{1}$ $+H c g_{1} a+\left(T g_{1}-T a\right) A g_{1}+H r g_{1} s k y\left(T g_{1}-T s k y\right) A g_{1}$

Where Tsky $=$ Ta-6 [31]

(b) Glass cover- 2
$I \tau_{g 2} \alpha_{g 2}+H r p_{1} g_{2}\left(T p_{1}-T g_{2}\right)+H c f_{1} g_{2}\left(T f_{1}-T g_{2}\right)=$ $H r g_{2} g_{1}\left(T g_{2}-T g_{1}\right)+H c g_{2} f_{2}\left(T g_{2}-T f_{2}\right)$

(c) Absorber plate -1

$l \alpha_{p} \tau_{g 1} \tau_{g 2}=H r p_{1} g_{2}\left(T p_{1}-T g_{2}\right)+H c p_{1} f_{2}\left(T p_{1}-T f_{2}\right)+$ $H r p_{1} p_{2}\left(T p_{2}-T p_{1}\right)+H c p_{1} f_{a}\left(T p_{1}-T f_{1}\right)$

(d) Absorber plate - 2

$$
\begin{aligned}
& I e_{f f} \alpha_{p}=H r p_{1} p_{2}\left(T p_{2}-T p_{1}\right)+H c p_{2} f_{a}\left(T p_{2}-T f_{1}\right)+ \\
& H r p_{2} a\left(T p_{2}-T a\right)+H c p_{2} a\left(T p_{2}-T a\right)
\end{aligned}
$$

Where, $l e_{f f}=(\mathrm{I} \cdot \rho \cdot \mathrm{Ar}) / \mathrm{Ap}$ effective solar radiation per unit area on the absorber plate - II

(e) Air flow -1

$H c g_{1} f_{1}\left(T g_{1}-T f_{1}\right)=\frac{\operatorname{mac}_{p_{2}} \Delta T J_{1}}{B L}+H c f_{1} g_{2}\left(T f_{1}-T g_{2}\right)$

(f) Air flow - 2

$H c g_{2} f_{2}\left(T g_{2}-T f_{2}\right)+H c p_{1} f_{2}\left(T p_{1}-T f_{2}\right)=\frac{\operatorname{mac}_{p p^{2}} \Delta T J_{2}}{B L}$

(g) Air flow- 3

$$
\begin{aligned}
& H c p_{2} f_{a}\left(T p_{2}-T f_{a}\right)+H c p_{1} f_{a}\left(T p_{1}-T f_{a}\right)=\frac{\operatorname{mac}_{p 2} \Delta T T_{3}}{B L} \\
& \mathrm{Tf}_{1}=\frac{\left(\mathrm{Tf}_{2,} \mathrm{O}+\mathrm{Ti}\right)}{2} \\
& \mathrm{Tf}_{2}=\frac{\left(\mathrm{Tf}_{2,0}, \mathrm{Tf}_{2}, 0\right)}{2} \\
& \mathrm{Tf}_{3}=\frac{\left(\mathrm{Tf}_{3}{ }^{2} \mathrm{O}+\mathrm{Tf}_{2} \mathrm{D}\right)}{2}
\end{aligned}
$$

Equations (1 to 7) are arranged in a Matrix [7x7] form. i.e. $[\mathrm{B}][\mathrm{T}]=[\mathrm{Z}]$

$\left[\begin{array}{ccccccc}\mathrm{Z}_{8} & -\mathrm{Hcg}_{1} \mathrm{f}_{1} & -\mathrm{Hrg}_{2} \mathrm{~g}_{1} & 0 & 0 & 0 & 0 \\ -\mathrm{Hcg}_{1} \mathrm{f}_{1} & \mathrm{Z}_{9} & -\mathrm{Hcf}_{1} \mathrm{~g}_{2} & 0 & 0 & 0 & 0 \\ -\mathrm{Hrg}_{2} \mathrm{~g}_{1} & -\mathrm{Hcf}_{1 \mathrm{~g}_{2}} & \mathrm{Z}_{10} & -\mathrm{Hcg}_{2} \mathrm{f}_{2} & -\mathrm{Hrp}_{1} \mathrm{~g}_{2} & 0 & 0 \\ 0 & 0 & -\mathrm{Hcg}_{2} \mathrm{f}_{1} & \mathrm{Z}_{11} & -\mathrm{Hcp}_{1} \mathrm{f}_{2} & 0 & 0 \\ 0 & 0 & -\mathrm{Hrp}_{1} \mathrm{~g}_{2} & -\mathrm{Hcp}_{1} \mathrm{f}_{2} & \mathrm{Z}_{12} & -\mathrm{Hcp}_{1} \mathrm{f}_{3} & -\mathrm{Hrp}_{1} \mathrm{p}_{2} \\ 0 & 0 & 0 & 0 & -\mathrm{Hcp}_{1} \mathrm{f}_{3} & \mathrm{Z}_{13} & -\mathrm{Hcp}_{2} \mathrm{f}_{3} \\ 0 & 0 & 0 & 0 & \mathrm{Hrp}_{1} \mathrm{p}_{2} & -\mathrm{Hcp}_{2} \mathrm{f}_{3} & \mathrm{Z}_{14}\end{array}\right]\left[\begin{array}{c}\mathrm{Tg}_{1} \\ \mathrm{Tf}_{1} \\ \mathrm{Tg} \mathrm{g}_{2} \\ \mathrm{Tf}_{2} \\ \mathrm{Tp_{1 }} \\ \mathrm{Tf_{3 }} \\ \mathrm{Tp_{2 }}\end{array}\right]=\left[\begin{array}{c}\mathrm{Z}_{1} \\ \mathrm{Z}_{2} \\ \mathrm{Z}_{3} \\ \mathrm{Z}_{4} \\ \mathrm{Z}_{5} \\ \mathrm{Z}_{6} \\ \mathrm{Z}_{7}\end{array}\right]$

Where

$Z_{1}=\alpha_{g 1} I+H c g_{1} a \cdot T a+H r g_{1} S k y \cdot T_{\text {sky }}$

$Z_{2}=\dot{m a} \frac{C_{p a}}{B L}$

$Z_{\mathrm{a}}=\tau_{g 2_{2}} \alpha_{g 2} I$

$Z_{\mathrm{a}}=\operatorname{ma} \frac{C_{\mathrm{pa}}}{B L}$

$Z_{5}=\tau_{g 1,} \tau_{g 2} \alpha_{p,} I$

$Z_{6}=\left(\mathrm{ma} \frac{\mathrm{qua}_{\mathrm{pa}}}{B L}\right) T_{f 2}$

$Z_{7}=\alpha_{p_{0}} l_{0} \rho A_{\gamma}+H r p_{2} a_{n} T_{a}+H c p_{2} a_{0} T_{a}$

$Z_{g}=H c g_{1} f_{1}+H r g_{2} g_{1}+H r g_{1} S_{g h y}+H c g_{1} a$

$Z_{g}=H c g_{1} T f_{1}+H r f_{1} g_{2}+\dot{m a} \frac{C_{p a}}{B L}$

$Z_{10}=H r p_{1} g_{2}+H c f_{1} g_{2}+H_{r g_{2} g_{1}}+H c g_{1} f_{1}$

$Z_{11}=H c g_{2} f_{2}+H c p_{1} f_{2}+\operatorname{ma} \frac{c_{p a}}{B L}$

$Z_{12}=H r p_{1} g_{2}+H c p_{1} f_{2}+H r p_{1} p_{2}+H c p_{1} f_{2}$

$Z_{1 a}=H c p_{2} f_{a}+H c p_{1} f_{a}+$ ma $\frac{c_{p a}}{B L}$ 
$Z_{14}=H r p_{1} p_{2}+H c p_{2} f_{1}+H c p_{2} a+H r p_{2} a$

The solar intensity available on inclined absorber plate I and the effective solar intensity on reversed absorber plate II are constant during the daytime. [31]

The mean temperature of components and air flow was determine by using MS Excel

$[\mathrm{T}]=[\mathrm{B}]^{-1}[\mathrm{Z}]$

3.1 Input -MPSAH parameters and heat coefficients:

Solar intensity on inclined absorber plate and effective solar intensity on reversed absorber plate were calculated by using the method given by Lui and Jordan (1962).

The values computed by using Ms Excel were compared with the values absorbed during the experimentation. The repeatedly new values computed on MS excel were compared with the experimentally observed values up to get mean temperature difference less than $1^{\circ} \mathrm{C}$. Thus the mean temperature values of $\mathrm{Tf}_{1}, \mathrm{Tf}_{2}, \mathrm{Tf}_{3}, T g_{1}, \mathrm{Tg}_{2}, \mathrm{~T} \mathrm{p}_{1}$, and $\mathrm{T} \mathrm{p}_{2}$ was attained in three to seven iterations.

The MPSAH design parameters: $\mathrm{L}=200 \mathrm{~cm}, \mathrm{~B}=100 \mathrm{~cm}$, $\mathrm{H}=2.5 \mathrm{~cm}$, and coefficients: $\alpha_{p}=0.95, \alpha_{g}=0.05, \varepsilon_{p}=$ $0.9, \varepsilon_{g}=0.8, \tau_{g}=0.92$, Ambient Temperature $\mathrm{Ta}=25^{\circ} \mathrm{C}$, $\mathrm{T}_{\mathrm{i}}=27^{\circ} \mathrm{C}$ and $\mathrm{V}=100 \mathrm{~cm} / \mathrm{s}$.

Following formulae used to calculate thermal efficiency of $\mathrm{SAH}$,

$\eta_{\mathrm{c}}=\frac{\mathrm{m}_{\mathrm{z}} \mathrm{Cpa}\left(\mathrm{T}_{\mathrm{f}}-\mathrm{T}_{\mathrm{i}}\right)}{A I}$

Where

$\mathrm{Tf}$ is exit temperature of air in $\mathrm{SAH}$ and $\mathrm{Ti}$ is inlet temperature of air in SAH. The physical properties of air are consider as per available in literature by ONG [32];

Specific heat

$\mathrm{Cpa}=1.0057+0.0000669(\mathrm{~T}-27)$

Density

$\mathrm{P}=1.1774-0.00359(\mathrm{~T}-27)$

Thermal conductivity

$\mathrm{K}=0.02624+0.0000758(\mathrm{~T}-27)$

Viscosity

$\mu=[1.983+0.00184(\mathrm{~T}-27)] 10^{-5}$

The heat transfer coefficient was calculated,

Such as $\mathrm{Hw}=2.8+3.3 \mathrm{Vw}$

Where

$\mathrm{Hw}$ - convection heat transfer coefficient due to wind and

$\mathrm{V}$ is the wind velocity.

Hrgs $=\frac{\sigma \mathrm{gg}\left(\mathrm{Tg}_{\mathrm{g}}+\mathrm{T}_{\text {sky }}\right)\left(\mathrm{Tg}^{2}+\mathrm{T}_{\text {sky }}{ }^{2}\right)\left(\mathrm{Tg}_{\mathrm{g}}-\mathrm{T}_{\text {sky }}\right)}{\mathrm{Tg}-\mathrm{Ta}}$

$\mathrm{T}_{\mathrm{gk} y}$ Is the sky temperature, $\left(\mathrm{T}_{\mathrm{sky}}=\mathrm{Ta}-6\right)$

$\mathrm{Ut}=\left(\frac{1}{H w+H r g s}\right)^{-1}$

Following formulae used to calculate convective heat transfer coefficients,

$H=\frac{k}{d e} \mathbb{N u}$

Where $\mathrm{Nu}$ is Nusselt number and de is the equivalence diameter of the channel. For laminar flow region,

Nusselt number for $(\operatorname{Re}<2300)[22,24,32]$ :

$N u=5.4+\frac{0.00190\left[\operatorname{Re} P r\left(\frac{d R}{L}\right)\right]^{1.71}}{1+0.0056 a\left[\operatorname{Re} \operatorname{Pr}\left(\frac{d g}{L}\right)\right]^{1.71}}$

For transition flow region $(2300<\mathrm{Re}<6000)$

$\mathrm{Nu}=0.116\left(\operatorname{Re}^{2 / 3}-125\right) \operatorname{Pr}^{1} / 3\left[1+\left(\frac{\text { de }}{\mathrm{L}}\right)\right.$

For turbulent flow region

$\mathrm{Nu}=0.018 \operatorname{Re}^{0.8} \operatorname{Pr}^{0.4}$
$\operatorname{Re}=\frac{\text { pvde }}{{ }^{H}}$
de $=\frac{4 H}{2(W+H)}$

The mean temperature values were obtained by using all energy balance equations for each element of a MPSAH with reversed absorber and solve them by using matrix inversion method in MS Excel.

\section{COST ANALYSIS}

Annual cost (AC) per unit surface area was calculated. For that different cost factors have to be calculated. [33]. AHC- annual solar air Heater cost,

AMC- annual maintenance of SAH

ARV- annual reclaim value of SAH

APC- annual pumping costs in SAH

The annual solar air Heater cost (AHC) is calculated as:

$\mathrm{AHC}=\mathrm{CRF}$ X CI

Where

$\mathrm{CI}=\mathrm{CAH}+\mathrm{HSSC}+\mathrm{FC}$

And

$C R F=\frac{i(i+1)^{n}}{\left[i(i+1)^{n}-1\right]}$

Where $\mathrm{CI}$ is the capital investment in SAH, CRF is the capital recovery factor, $\mathrm{CAH}$ is the cost of the heater array, HSSC is the heater support structure cost and FC is the fabrication cost of SAH. The maintenance cost (MC) of the SAH is considered to be $10 \%$ of the AHC.

The annual reclaim value (ARV) is calculated as:

$\mathrm{ARV}=\mathrm{RFF} \times \mathrm{SV}$

Where

RFF the reclaim fund factor

$F F=i /\left[(i+1)^{n}-1\right]$

And

$\mathrm{RV}=0.1 \mathrm{CI}$

The annual pumping cost is calculated as:

$A P C=\left(\frac{m \Delta p}{\rho}\right) t_{o p} c_{e}$

Where $t_{o p}$ - time of operation, cost of electricity (Ce) and $(\Delta \mathrm{P})$ is a pressure drop across each passage is calculated by using Eq. (48).

$\Delta P=\left(\frac{m}{A_{a p}}\right)^{2} \frac{1}{\rho}\left(\frac{l}{d}\right)^{2} f$

where

Aap - air passage area equal to ( $\mathrm{d} \times \mathrm{L})$,

$f$ - Friction factor for Reynolds number has been calculated by formulae (49) [34].

For $\operatorname{Re}<2550$,

$f=\frac{24}{R_{\mathbf{e}}}+0.9\left(\frac{\mathrm{d}}{\mathrm{L}}\right)$

For $2550<\operatorname{Re}<10^{4}$

$f=0.0094+2.92 R_{e}^{-0.15}\left(\frac{d}{L}\right)$

For $10^{4}<R_{e}<10^{5}$

$f=0.059 R_{e}^{-0.2}+0.73\left(\frac{d}{L}\right)$

The pumping power is given by El-Sebaii et al. [35]

$P_{f=\frac{m S P}{p}}$

The pressure drop $(\Delta \mathrm{P})$ can be calculated as

$\Delta P=\Delta P_{\text {ch } 1}+\Delta P_{\text {ch } 2}$

Therefore, the annual cost (AC) per unit area is calculated as [36]

$\mathrm{AC}=\mathrm{AHC}+\mathrm{MC}+\mathrm{APC}-\mathrm{ARV}$

The annual energy gain (AEG) can be determined by using following equation [37]. 
$A E G=m C\left(T_{0}-T_{i}\right) t_{\text {op }}$

\section{RESULT \& DISCUSSION}

1. Thermal Analysis:

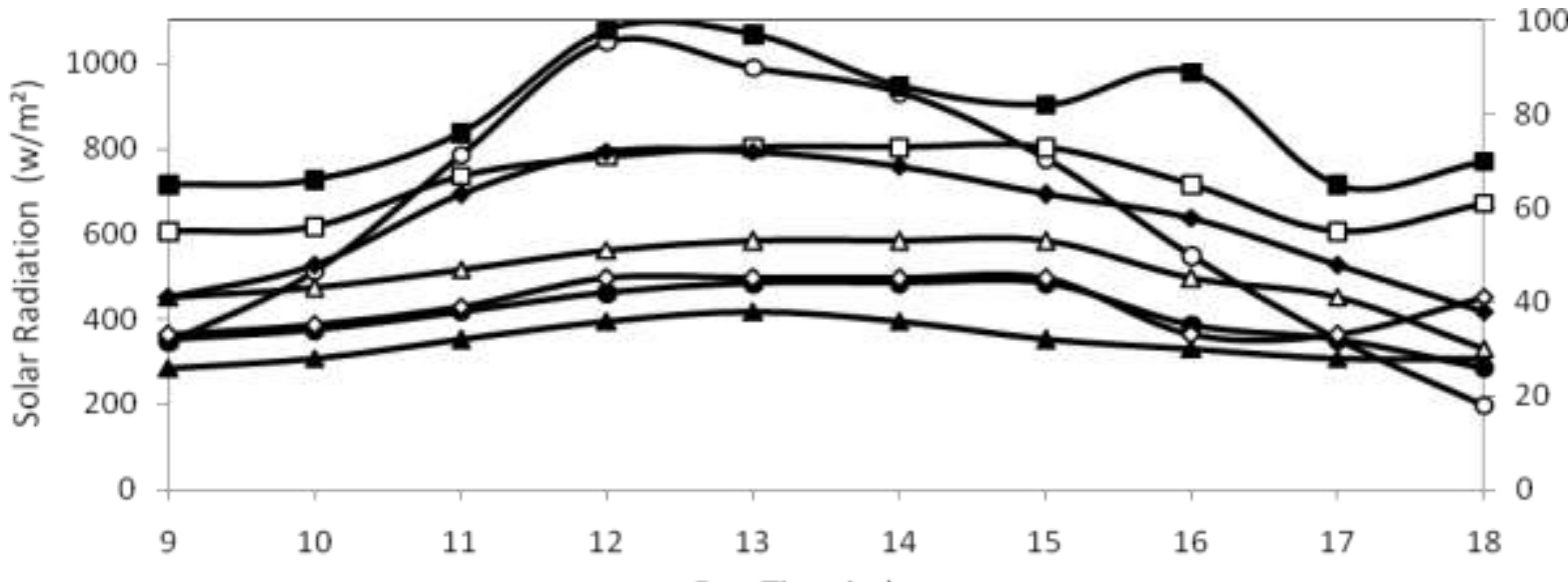

Day Time in hours
The temperature of air stream- 1, 2, 3 i.e. $T f_{1} \times T f_{2}, T f_{a}$, Temperature of glass cover- $1 \& 2$ i.e. $T g_{1}, T g_{2}$, Temperature of absorber plate $1 \& 2$ are $T p_{1}, T p_{2}$ respectively. These temperatures have been calculated by using energy balance equations (1-7) with Excel software.

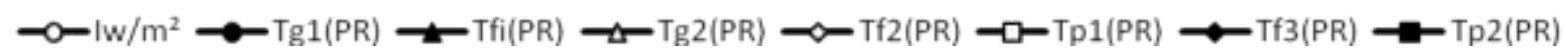

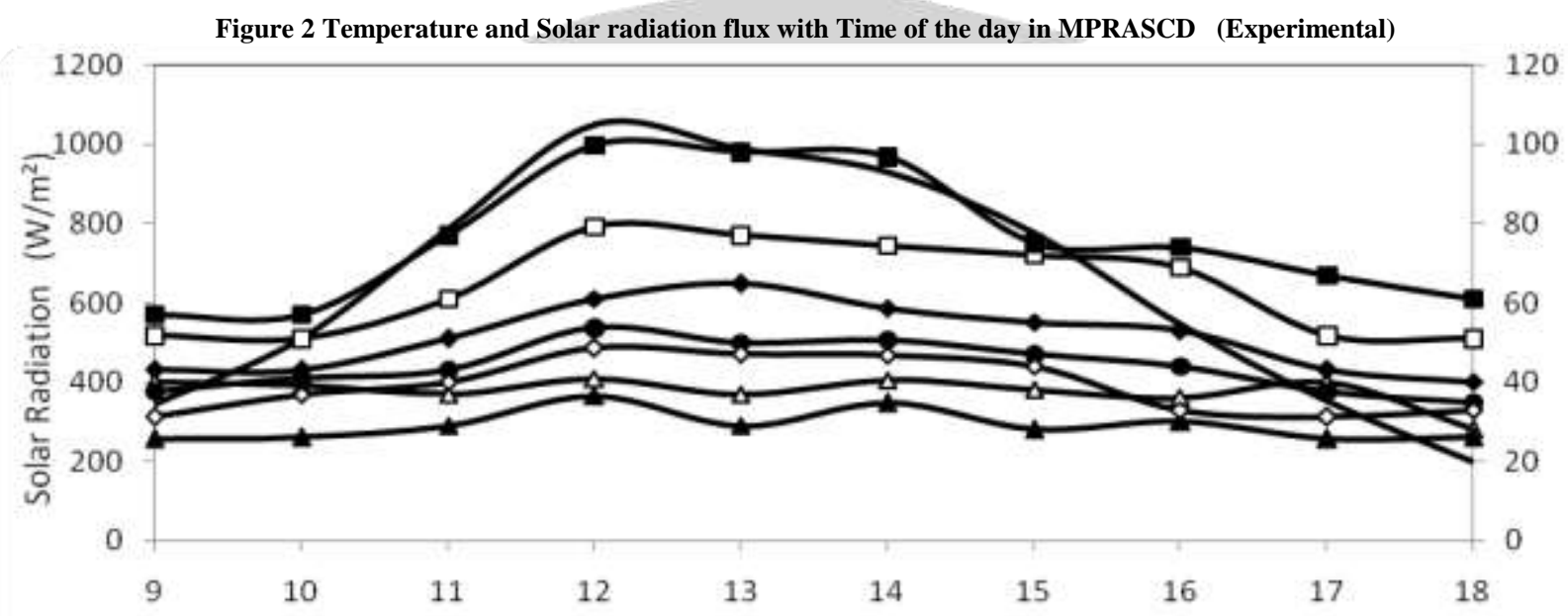

Day Time in Hours

$\longrightarrow \mathrm{w} / \mathrm{m}^{2} \longrightarrow \mathrm{Tg} 1(\mathrm{TH}) \longrightarrow \mathrm{Tf} 1(\mathrm{TH}) \longrightarrow \mathrm{Tg} 2(\mathrm{TH}) \longrightarrow \mathrm{Tf} 2(\mathrm{TH}) \rightarrow \mathrm{Tp} 1(\mathrm{TH}) \longrightarrow \mathrm{Tf} 3(\mathrm{TH}) \rightarrow \mathrm{Tp} 2(\mathrm{TH})$

Figure 3 Variation of Temperature and Solar flux with Time of the day in MPRASCD (Theoretical)

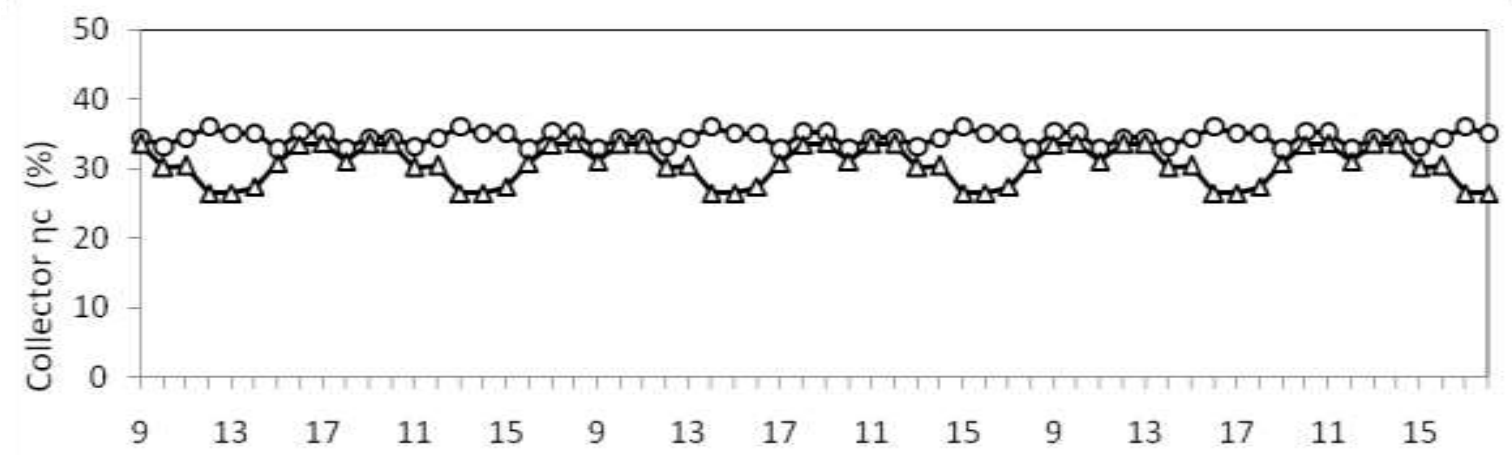

Day Time in Hours

$$
\sim \text { TH } \quad \longrightarrow \text { PR }
$$

Figure 4 Variation of efficiency $\left(\eta_{c t h} \& \eta_{c p r}\right)$ with Day Time in MPRASCD

Experimentation was done at Nagpur city in Maharashtra India, and results calculated for solar intensity and ambient temperature at available climate condition. Experimental and theoretical values of temperature of air stream, glass 
covers and absorber plates are shown in figure 2 and figure 3. Mathematical model was solved by using average solar intensity and ambient air temperature. An absorber plates gets heated due to solar radiation available during sunshine hours. Solar intensity received by absorber plate-I \& II are equal but the temperature of reversed absorber plate-II is greater than inclined absorber plate-I due to a smaller amount of convective and radiation losses during day hours. From figures it has been noted that the rise in air stream temperature is sufficient to dry a variety of agriculture food product. As the temperature of inclined absorber plate $\left(T p_{1}\right)$ was less than the reversed absorber plate $\left(T p_{2}\right)$ in MPSCD during the period of drying.

From the Figure 4 it can be noted that the experimentally attained collector efficiency is little less than the theoretical collector efficiency obtained from the thermal analysis. Average collector efficiency obtained from the formulation and experimental for MPRASCD is $36.41 \%$ and $33.64 \%$ respectively.

\section{Cost Analysis}

The cost of the flat plate collector was equal to Rs. $10000 / \mathrm{m}^{2}$. The cost of supporting structure was assumed to be Rs. $4500 / \mathrm{m}^{2}$. The fabrication cost of collector was approximately equal to Rs. $7600 / \mathrm{m}^{2}$ for reversed absorber and Rs. $5100 / \mathrm{m}^{2}$ for without reversed absorber and reflector. The electric power consumed by fan to circulate the air inside the dryer was approximately Rs. $8 / \mathrm{kW} \mathrm{h}$. The interest rate (i) and collector life (n) was assumed as $10 \%$ and 10 years respectively. Approximately 275 sunny days were available in a year with average wind velocity of $1 \mathrm{~m} / \mathrm{s}$ Mani A. et al. [37] and $10 \mathrm{~h}$ per day in India (From 8 am to $6 \mathrm{pm})$. By using model presented above the ratio of Annual cost and Annual energy Gain (AC/AEG) were computed at constant mass flow rate $0.0269 \mathrm{Kg} / \mathrm{m}^{2}$ and for different solar intensity for the multi pass solar air heater with and without reversed absorber. Table 1 shows the AC/AEG values of the Multi pass solar collector with and without reversed absorber for constant mass flow rate and different solar intensity. Multi-pass solar air heater with reversed absorber and reflector is more gainful compared to the multi-pass solar collector without reversed absorber.

\begin{tabular}{|c|c|c|c|c|c|}
\hline \multirow{2}{*}{ Time } & \multirow{2}{*}{$\left(\mathbf{W} / \mathbf{m}^{2}\right)$} & (To-Ti) & (To-Ti) & \multicolumn{2}{|c|}{ Annual Cost/Annual Energy Gain } \\
\cline { 3 - 6 } & 390 & $\begin{array}{c}\text { With Reversed } \\
\text { Absorber }\end{array}$ & $\begin{array}{c}\text { Without Reversed } \\
\text { Absorber }\end{array}$ & With Reversed Absorber & Without Reversed Absorber \\
\hline $9 \mathrm{am}$ & 531 & 15 & 8 & 0.503 & 0.5358 \\
\hline $10 \mathrm{am}$ & 623 & 20 & 11 & 0.3535 & 0.3793 \\
\hline $11 \mathrm{am}$ & 895 & 29 & 18 & 0.2398 & 0.2591 \\
\hline $12 \mathrm{noon}$ & 910 & 36 & 23 & 0.174 & 0.172 \\
\hline $1 \mathrm{pm}$ & 880 & 35 & 21 & 0.174 & 0.172 \\
\hline $2 \mathrm{pm}$ & 849 & 33 & 24 & 0.193 & 0.199 \\
\hline $3 \mathrm{pm}$ & 613 & 29 & 23 & 0.220 & 0.229 \\
\hline $4 \mathrm{pm}$ & 358 & 25 & 15 & 0.335 & 0.357 \\
\hline $5 \mathrm{pm}$ & 348 & 14 & 9 & 0.508 & 0.545 \\
\hline $6 \mathrm{pm}$ & 12 & & 0.614 & 0.681 \\
\hline
\end{tabular}

\section{CONCLUSION}

A mathematical model and method of obtaining solution for finding thermal efficiency of multi -pass solar air heater with and without reversed absorber and reflector was presented. Steady state condition was assumed to determine the temperature from energy balance equation. Excel software including a matrix inversion method was used. For the different intensity of solar radiation, the theoretical and experimental outlet temperatures of the multi-pass solar air heater with and without reversed absorber were calculated and compared to predict the performance. Thermal efficiency of solar air heater is strongly depending on the solar intensity harness by absorber plate. Hence, increase in the solar intensity on the absorber plate and reduction in radiation and convection heat losses results in higher efficiencies. The optimum energy efficiency is approximately $38 \%$, which was observed at the mass flow rate of $0.0269 \mathrm{~kg} / \mathrm{s}$.

The performance curves of the multi-pass solar collector with and without reversed absorber, which included the effects of reversed absorber and solar intensity on the energy efficiency of the solar collector, were obtained. The multi-pass solar air heater with reversed absorber and reflector is more cost-effective compared to the multi-pass solar collector without reversed absorber.

\section{REFERENCES}

[1] RET Screen. Chapter; "solar air heating project analysis, clean energy project analysis," textbook, catalogue no: M39-100/2003E-pdf. International Clean Energy Decision Support Centre, Canada; 2004.

[2] Gill RS, Singh S, Singh PP. "Low cost solar air heater,". Energy Convers Manag 2012;51:131-42.

[3] Sakhrieh A, Al-Ghandoor A. "Experimental investigation of the performance of five types of solar collectors," Energy Convers Manage 2013;65:715-20.

[4] Chandra R, Sodha MS. "Testing procedures for solar air heaters: a 1991;32:11-32.

[5] Fudholi A, Sopian K, Ruslan MH, AlGoul MA, Sulaiman MY. "Review of solar dryers for agricultural 
and marine products," Renew Sustain Energy Rev 2010;14:1-30.

[6] Yeh HM, Ho CD, Hou JZ. "Collector efficiency of double-flow solar air heaters with fins attached," Energy 2002;27:715-27.

[7] Moummi N, Ali SY, Moummi A, Desmons JY. "Energy analysis of a solar air collector with rows of fins," Renew Energy 2004;29:2053-64.

[8] Pakdaman MP, Lashkari A, Tabrizi HB, Hosseini R. "Performance evaluation of a natural-convection solar air-heater with a rectangular- finned absorber plate,' Energy Convers Manage 2011;52:1215-25.

[9] Karim MA, Hawlader MNA. "Performance investigation of flat plate, v-groove and finned air collectors," Energy 2006;31:452-70.

[10] Yeh HM, Ho CD. "Effect of external recycle on the performances of flat-plate solar air heaters with internal fins attached," Renew Energy 2009;34:1340-7.

[11] Ammari HD. "A mathematical model of thermal performance of a solar air heater with slats," Renew Energy 2003;28:1597-615.

[12] Naphon P. "Heat transfer characteristics and pressure drop in channel with $\mathrm{v}$ corrugated upper and lower plates," Energy Convers Manage 2007;48:1516-24.

[13] Singh S, Chander S, Saini JS. "Exergy based analysis of solar air heater having discrete V-down rib roughness on absorber plate," Energy 2012;37:749-58. [14] Mahboub C, Moummi N. "Calculation of the glass cover temperature and top heat loss coefficient for 60 vee corrugated solar collectors with single glazing," Solar Energy 2012;86:804-8.

[15] Hedayatizadeh M, Ajabshirchi A, Sarhaddi F, Safavinejad A, Chaji H. "Analysis of exergy and parametric study of a v-corrugated solar Heat Mass Transfer 2012:1-13.

[16] Dovic' D, Andrassy M. 'Numerically assisted analysis of flat and corrugated plate solar collectors thermal performances," Solar Energy 2012;86:2416-31.

[17] Sopian K, Alghoul MA, Alfegi EM, Sulaiman MY, Musa EA "Evaluation of thermal efficiency of doublepass solar collector with

Renew Energy 2009;34:640-5.

[18] Ramadan MRI, El-Sebaii AA, Aboul-Eneein S, ElBialy E. "Thermal performance of packed bed doublepass solar air heater," Energy 2007;32:1524-35.

[19] Aldabbagh LBY, Egelioglu F, Ilkan M. "Single and double pass solar air heaters with wire mesh as packing bed," Energy 2010;35:3783-7.

[20] Matrawy KK. "Theoretical analysis for an air heater with a box-type

1998;63(3):191-8.

absorber," Solar Energy

[21] Abdullah AH, A-Ziyan HZ, Ghoneim AA. "Thermal performance of flat plate solar collector using various arrangements of compound honeycomb," Energy Convers Manage 2003;44:3093-112.

[22] Naphon P. "On the performance and entropy generation of the double-pass solar air heater with longitudinal fins," Renew Energy 2005;30:1345-57.

[23] Metwally MN, Abou-Ziyan HZ, El-Leathy AM. "Performance of advanced corrugated-duct solar air collector compared with five conventional designs,"
[24] Jain D., "Modeling the performance of the reversed absorber with packed bed thermal storage natural convection solar crop dryer," J $\quad$ Food Eng 2007; 78: 637-47.

[25] Choudhury C, Chauhan PM, Garg HP. "Performance and cost analysis of two pass solar air heater," Heat Recov Syst CHP 1995;15(8):755-73.

[26] Choudhury C, Chaulan PM, Garg HP, Garg SN. "Costbenefit ratio of triple pass solar air heaters," Energy Convers Manage 1996;37(1):16-95.

[27] Biondi P, Cicala L, Farina G. "Performance analysis of solar air heaters of conventional design,". Solar Energy 1988;41(1):101-7.

[28]Vijay Khawale, Shashank Thakare. "Modelling and experimental studies on solar crop dryer with reversed Absorber type solar air heater," International journal of Enery and power Engineering, WASET, France, Vol.12 N0. 3, 2018

[29] Choudhury C, Chauhan PM, Garg HP." Economic design of rock bed storage device for storing solar thermal energy," Solar Energy 1995;55(1):29-37.

[30] A. Fudholi, K. Sopian, M. H. Ruslan, M. Y. Othman, and M. Yahya,M., "Thermal efficiency of double pass solar collector with longitudinal fins Absorbers," American Journal of Applied Sciences, vol. 8, no. 3, pp. 254-260, 2011.

[31] Zhiqiang Y. "Development of solar thermal systems in China," Solar Energy Mater Solar 2005; 86:427-42.

[32]K.S. Ong, "Thermal performance of solar air heaters: mathematical model and solution procedure," Solar Energy,55(2):93-109, 1995.

[33] Pakdaman MP, Lashkari A, Tabrizi HB, Hosseini R. "Performance evaluation of a natural-convection solar air-heater with a rectangular-finned absorber plate," Energy Convers Manage 2011;52:1215-25.

[34] Akpinar EK. "Drying of mint leaves in solar dryer and under open sun: modeling, performance analyses," Energy Convers Manage 2010;51: 2407-18.

[35]Akpinar EK, Kocyigit F. "Energy and exergy analysis of a new flat- plat solar air heater having different obstacles on absorber plates," Appl Energy 2010;87:3438-50.

[36] Sabatelli V, Marano D, Braccio G, Sharma VK. "Efficiency test of solar collector: uncertainty in the estimation of regression parameters and sensitivity analysis," Energy Convers Manage 2002;43:2287-95.

[37] Mathioulakis E, Voropoulos K, Belessiotis V. "Assessment of uncertainty in solar collector modeling and testing," Solar Energy 1999;66(5):337-47.

Renew Energy 1997;10(4):519-37. 